\title{
Introduction to gender editorials
}

Valerie W. Rusch, MD

Editorial Note: This is the final group of editorials in "The Gender Initiative," a series published in the Journal beginning with the September 2003 issue, addressing gender differences in the surgical treatment of cardiac, vascular, and thoracic disease. Dr Andrew Wechsler, the editorialists, and I sincerely hope that the readers found the series to be both informative and provocative.

\section{Nancy A. Nussmeier, MD} Texas Heart Institute

See related editorials on pages 346 and 352.

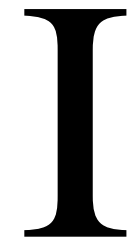

n previous issues of the Journal, several editorials have discussed gender differences in cardiovascular disease. In this issue, editorials focus on gender-related issues in general thoracic surgery, highlighting two areas-lung cancer and lung transplantation. Of course, these

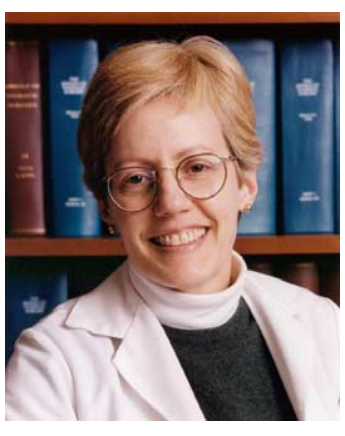
topics do not address all of the potential gender-related differences in our subspecialty. One could ask, for example, why some benign pulmonary diseases (eg, lymphangioleiomyomatosis or chronic eosinophilic pneumonia) have a strong female predominance or why esophageal adenocarcinoma in Barrett's esophagus is far more common in men than in women. Indeed, these two editorials ask more questions than can be currently answered and emphasize the opportunities for research in gender-related differences. In the age of molecularly based diagnosis, it should be possible to study whether perceived gender differences are real and, if so, why. Potential differences in treatment outcomes between men and women also warrant investigation. We hope that these editorials will prompt further discussion and encourage research.
From the Thoracic Service, Department of Surgery, Memorial Sloan-Kettering Cancer Center, New York, NY.

Received for publication June 22, 2004; accepted for publication June 23, 2004.

Address for reprints: Valerie W. Rusch, MD, Chief, Thoracic Service, Department of Surgery, Memorial Sloan-Kettering Cancer Center, 1275 York Ave, Room C-867, New York, NY 10021 (E-mail: ruschv@ mskcc.org).

J Thorac Cardiovasc Surg 2004;128:345

$0022-5223 / \$ 30.00$

Copyright $\odot 2004$ by The American Association for Thoracic Surgery

doi:10.1016/j.jtcvs.2004.06.023 